\title{
Synthesis
}

\section{Preparing for climate change: an evaluative framework for prioritizing adaptation measures in Nepal}

\author{
Asheshwor Man Shrestha \\ PO Box 8975 EPC631, Lalitpur, Nepal
}

\begin{abstract}
Severe potential climate threats for Nepal are expected to impact water resource, agriculture, biodiversity and livelihood. While adaptation and mitigation are both valid policy options to tackle climate change, it is advantageous for developing countries to opt for adaptation. It is also desirable that the most feasible adaptation actions be applied to protect development investment from climate risks and to ensure maximum preparedness. Adaptation strategies consist of a set of measures that are highly effective, affordable, technically and socially feasible and contribute towards disaster risk reduction. An evaluative framework using scoring matrix is utilized to prioritize adaptation options. Adaptation options for threat areas identified for Nepal are analyzed based on literature in the context of Nepal as well as for Asia and for least developed countries (LDCs). The measures are evaluated across multiple categories like public/private costs, effectiveness, social/cultural feasibility, speed, support for mitigation and aid in disaster preparedness. Based on the scoring matrix evaluation, following measures appear most feasible: (1) water conservation and management; (2) investment in smaller hydro-power plants; (3) research/planting of climate resistant crops; (4) diversification of agriculture; (5) development of early warning system for disasters; and (6) flood control measures downstream. Due to financial and technical constraints, it is advantageous to opt for 'no-regrets' strategies which benefit even without climate change. These set of measures can be carried out at low costs to reap sure benefits and should be prioritized for execution through environmental policies especially climate policies.
\end{abstract}

Key-words: Adaptation; climate change; climate policy; disaster risk reduction; Nepal.

\section{Introduction}

Climate change impacts are being realized globally, and Nepal with large dependence on resources and limited development fund is among the most vulnerable under these conditions. Although all places in the region are exposed with similar threats, the impact felt by each area will be different. The impacts borne by each community depend on various factors like location, geological condition, local weather, resiliency and preparedness of the community and the ability to adapt to adverse effects of climate change. The location's exposure of a unique micro-climate, resource base, infrastructure, technological capability, economic capacity and its reaction

For correspondence, e-mail address: mail@asheshwor.com.np to climate change varies accordingly. Responses to climate change should correspond to local conditions through an inclusive process that integrates climate change issues with technical capabilities and the capacity of the institutions and the community.

This paper aims to utilize an evaluative framework to prioritize climate change adaptation options in the context of Nepal's geopolitical and socioeconomic status the output of which is a bundle of adaptation measures that are most feasible for Nepal's while considering various constraints. The findings can be taken as an input to shape adaptation policy tools especially in formulating climate policies and prioritizing funding for adaptation measures.

It is also found that while many mitigation and adaptation projects are underway to tackle climate change in Nepal, it 
should be stressed that investment in adaptation will yield sure benefits, and no regrets adaptation measures also exists for Nepal which is beneficial even if climate change benefits fail to occur. Moreover, measures which aid in disaster preparedness are wise investments for Nepal where development fund is scarce. Some adaptation measures also indirectly aid in mitigation efforts which can be considered in evaluating measures.

\section{Adaptation to Climate Change}

According to framework put forward by the Intergovernmental Panel on Climate Change (IPCC), policy responses on climate change impacts are based on net or residual impacts that are the impact which is felt after natural or autonomous adaptations (IPCC 2007). Both mitigation and adaptation are suggested policy options to tackle climate change by United Nations Framework Convention on Climate Change (UNFCCC). Mitigation policy addresses the human influence on climate change by controlling on greenhouse gas (GHG) emissions and encouraging carbon sinks. In comparison with total world emissions of GHGs, the emission from Nepal is very small and thus the impact of reducing $\mathrm{CO}_{2}$ emissions from is going to be negligible. Also, even with complete adherence to the Kyoto protocol, which is aimed at GHGs under the UNFCCC framework, climate change impacts worldwide are not expected to be less severe (Parry et al. 1998). This is not to argue that Nepal should end all mitigation efforts and focus only on adaptation. Initiatives to increase energy efficiency and use of renewable energy should be of advantage to Nepal in the long run as it will pave a path towards sustainable energy and help in bio-diversity conservation. Least Developed Countries (LDCs) can be considered the least responsible for climate change as the amount of GHG emissions is very small but the problems are made worse in LDCs by the lack of means to adapt. LDCs also lack the finances, technology, and infrastructure to have a say in the international climate change regime (Cornell 2010).

Adaptation is a planned approach (or active approach) that deals with modifying impacts or vulnerability of systems to climate change and its subsequent effects (Smit et al. 1999). According to the IPCC an adaptation consist of "adjustment in natural or human systems in response to actual or expected climatic stimuli or their effects, which moderates harm or exploits beneficial opportunities” (IPCC 2007). IPCC also delineates three types of adaptations: (a) anticipatory or proactive adaptation that takes place before impacts of climate change are observed; (b) autonomous or spontaneous adaptation which does not constitute a conscious response to climatic stimuli but is triggered by ecological changes in natural systems and by market or welfare changes in human systems; and (c) planned adaptation that is the result of a deliberate policy decision, based on an awareness that conditions have changed or are about to change and that action is required to return to, maintain, or achieve a desired state.

Adaptation to climate change consists of modifications of ecological and social systems to accommodate climate change effects so that the system stays in operation. Adaptation to climate change can be implemented in two ways (Barnett 2001): (a) through modifying systems to accommodate longterm incremental change, (b) through resilience which consists of modifying systems to enable them to absorb and respond to short-term changes without passing critical threshold limits and so switching into alternative states of equilibrium.

As outlined later in this paper, both of these strategies can be applied as adaptation measures in Nepal. Delaying adaptation due to uncertainties in the predictions and in hope of better and cheaper technology to adapt in the future is not an option for Nepal as threats are imminent and directly related with livelihood and development.

\section{Climate Change in Nepal}

The main threats of climate change in Nepal have been identified mostly to impact in the sectors of water resource, agriculture, biodiversity and livelihood (Table 1). Numerous adaptation options which enable the ecosystem and the society to flourish even in the advent of climate change exists but adaptation has its costs and the effectiveness of each measure varies by location. Many of these measures have been applied elsewhere to adapt to climate change and many adaptation practices are also ongoing in Nepal. It is important that investment decisions are made wisely especially in the context of Nepal where development funds are limited.

Exposure to climatic hazard and vulnerability to climate change threats vary considerably between regions and sectors. There are also various degrees of uncertainty associated with climate change impacts. Impacts like carbon dioxide concentration and temperature are certain and highly likely respectively but variability and extreme events have less certainty (Downing et al. 1997; IPCC 2007). 
Table 1. Summary of climate change effect and impact for water, agriculture, biodiversity and natural hazards, format adapted from Downing et al. (1997), where the analysis has been done for the case of Africa.

\begin{tabular}{|c|c|c|c|}
\hline Climate Change Component & Effect & Impact & Where ${ }^{1}$ \\
\hline Increased air temperature & $\begin{array}{l}\text { Faster floral growth; } \\
\text { increased transpiration but } \\
\text { over shorter growing season; } \\
\text { reduced runoff and reduced } \\
\text { ground water recharge; } \\
\text { higher demand for water } \\
\text { irrigation }\end{array}$ & $\begin{array}{l}\text { Changes in water yield; } \\
\text { reduced economical yield } \\
\text { for agriculture; }\end{array}$ & $\begin{array}{l}\text { All places, more change on maximum } \\
\text { temperature than minimum } \\
\text { temperature; decreasing maximum } \\
\text { trend in the plains; variation in annual } \\
\text { mean temperature - decreasing in } \\
\text { northern parts and increasing in } \\
\text { southern parts; isolated pockets do not } \\
\text { confer to regional trend }\end{array}$ \\
\hline $\begin{array}{l}\text { Change in seasonal } \\
\text { precipitation }\end{array}$ & $\begin{array}{l}\text { Change in soil moisture; } \\
\text { change in river runoff and } \\
\text { ground water discharge }\end{array}$ & $\begin{array}{l}\text { Change in agricultural } \\
\text { yields; changes in projected } \\
\text { yield of hydropower } \\
\text { reservoirs; change in water } \\
\text { quality }\end{array}$ & $\begin{array}{l}\text { Both increasing and decreasing trend } \\
\text { with regional patterns but with } \\
\text { exceptions }\end{array}$ \\
\hline $\begin{array}{l}\text { Change in Spatial patterns of } \\
\text { temperature and } \\
\text { precipitation }\end{array}$ & $\begin{array}{l}\text { Shift in agro-climatic } \\
\text { suitability; shift in basin } \\
\text { hydrology (surplus and deficit } \\
\text { regions) }\end{array}$ & $\begin{array}{l}\text { Changes in cropping } \\
\text { systems; changes in } \\
\text { infrastructure to water } \\
\text { supply }\end{array}$ & $\begin{array}{l}\text { Both increasing and decreasing trend in } \\
\text { different regions }\end{array}$ \\
\hline $\begin{array}{l}\text { Change in variability of } \\
\text { precipitation }\end{array}$ & $\begin{array}{l}\text { Changes in water stress } \\
\text { between rainfall events; } \\
\text { changes in peak runoff }\end{array}$ & $\begin{array}{l}\text { Increased requirement for } \\
\text { storage, in marketed } \\
\text { products, sustenance crops } \\
\text { and water supply systems }\end{array}$ & $\begin{array}{l}\text { Historical trend show different extreme } \\
\text { rainfall distribution trend over annual or } \\
\text { seasonal trend. }\end{array}$ \\
\hline Change in water availability & $\begin{array}{l}\text { Water scarcity; stress in } \\
\text { agricultural production }\end{array}$ & $\begin{array}{l}\text { Food production will } \\
\text { decline; increased } \\
\text { requirement for storage; } \\
\text { stress on water supply } \\
\text { system }\end{array}$ & $\begin{array}{l}\text { Historic trend suggest large inter-annual } \\
\text { variations which will increase wet and } \\
\text { dry period with any further variation in } \\
\text { precipitation }\end{array}$ \\
\hline Change in flood hazard & $\begin{array}{l}\text { Increased precipitation will } \\
\text { increase run-off; retreating } \\
\text { glaciers can cause GLOF }\end{array}$ & $\begin{array}{l}\text { Increased erosion, } \\
\text { increased sedimentation } \\
\text { flow; increased hazard } \\
\text { from flood and landslides; } \\
\text { risk for hydropower plants }\end{array}$ & $\begin{array}{l}\text { River systems will be affected. } \\
\text { Settlements and infrastructures near } \\
\text { rivers are most at risk }\end{array}$ \\
\hline Loss of biodiversity & $\begin{array}{l}\text { Temperature and } \\
\text { precipitation range not } \\
\text { optimal for biodiversity }\end{array}$ & $\begin{array}{l}\text { Loss of native plants; } \\
\text { migration of animals }\end{array}$ & $\begin{array}{l}\text { Native species of plants have been under } \\
\text { stress from invasive species in recent } \\
\text { years. }\end{array}$ \\
\hline $\begin{array}{l}\text { Proliferation of invasive } \\
\text { species }\end{array}$ & $\begin{array}{l}\text { Changed climate favors } \\
\text { invasive species }\end{array}$ & $\begin{array}{l}\text { Native plant species cannot } \\
\text { survive; traditional crops } \\
\text { will be wiped out }\end{array}$ & $\begin{array}{l}\text { Invasive species have been moving } \\
\text { towards higher altitudes in some places. }\end{array}$ \\
\hline
\end{tabular}

Due to the constraints of fund, geographical position, lack of expertise and urgency of actions, it is desirable that only the most feasible adaptation actions be applied first to ensure maximum possible adaptation towards climate change events. Finding which adaptation is best is not only important for making future plans for Nepal but also essential for riskassessment of development funds as donor organizations have already started to assess their potential investments for climate risks (Agrawala et al. 2003). Considering the vulnerability of developing nation like Nepal to adverse effects of climate change, planned adaptation measures are most appropriate. An adaptation strategy should consist of a set of measures that is highly effective, affordable, and technically and socially feasible.

Smit and Pilifosova (2001) have outlined the priority areas for adaptation particularly for poor countries. The areas include land and water resources, food productivity and disaster planning and preparedness (Smit and Pilifosova 2001). The authors further stress that adaptations are made difficult by the poor resilience in most Asian countries in these sectors. Moreover, besides climate change, a wide range of problems already prevail in poorer regions. Adaptation hence should be closely linked with development activities, and should form 
important criteria in evaluation adaptation options (Smit and Pilifosova 2001).

The National Adaptation Plan of Action (NAPA) report for Nepal illustrates a prioritized list of actions also reiterating similar areas of focus with emphasis on community based measures for adaptation and disaster preparedness, ecosystem management and climate responsive urban settlements (Ministrey of Enviornment 2010). Sharma and Shakya (2006) have also stressed that climate change impact analysis should be done at a local level to yield a more accurate picture. The authors have analyzed the specific case of Bagmati and have stated that failure to adapt will result in water and power shortages (Sharma and Shakya 2006). With a nation already grappling with power shortages, this shows the gravity of the situation. Events of flooding in Nepal, although not directly attributed towards climate change, show the vulnerability of natural disasters and demonstrate that potential threats might increase in the event of climatic variability (Moench 2010). Agrawal et al. (2003) have prioritized water, food security, ecosystem and biodiversity, Glacial Lake Outburst Flooding (GLOF) and run-off variability, sediment loading, increased evaporation loss as most strong impacts of climate change in Nepal.

\section{Climate Change Adaptation Measures for Nepal}

The selection of adaptation measure depends on many factors like the cost of implementation, resources available, certainty of the threat and the severity of the threat. Besides these, adaptation measures' success also depends on the acceptability by the stakeholders, timeframe that is acceptable, potential social impact of the measure, institutional capacity of the community, and capacity to sustain the measure over time (Simpson et al. 2008). Adaptation strategies should include measures that reap the benefits of the impacts and minimize negative effects. Some beneficial impacts from increased temperature are seen in the areas of agriculture as discussed later in this paper. The threats from climate change are also not evenly spread across region. Although regional patterns of changes are observed, there are pockets with different pattern from regional change (Practical Action 2009). The impacts and hence the measures also vary from region to region which requires local level study and planning.
Some of the major threats and adaptation measures specific for Nepal are discussed in the following paragraphs.

Water availability is expected to decline with projected climate change impacts (IPCC, 2007; Ministrey of Enviornment 2010). In the Himalayas, retreating glaciers have been documented extensively which will impact river systems. Many settlements and urban areas in Nepal are already under stress from lack of water supply. Proper management of water is an adaptation strategy that will prove beneficial even without advent of climate change impacts as projected. Agricultural sector is also linked to water and adaptation measures like irrigation management and switching to less water demanding crops have been proposed (Ministry of Population and Environment 2004). Water harvesting, water recycling and water conservation techniques are low to medium cost options should also be encouraged, especially in urban areas.

Agriculture is one of the sectors which deemed to have considerable impact from climate change. Threats from rising temperatures, changing precipitation patterns, flooding and excess carbon dioxide, there have been many adaptation attempts -both planned and unplanned. Temperature will have an initial increase in production of rice and wheat but will decrease after a certain temperature is reached (Malla 2008; Ministry of Population and Environment 2004). Farmers in Nepal already use many adaptation measures to adapt against a variety of adverse impacts besides climate change (Regmi and Paudyal 2009). Some positive impacts from climate change in the agricultural sector in Nepal which will increase yield are seen although many negative impacts in agriculture also exist. The author further illustrates that current adaptation by farmers are also underway but on an ad-hoc basis (Tiwari et al. 2010).

Lack of rainfall is expected to impact rice production which relies heavily on rainfall. Climate change impacts pose additional threat to agricultural sector in Nepal which is already laden with problems of irrigation, food storage facility and lack of transport. Adaptation measures require a change in cropping pattern, crop diversification, and introduction of adaptive varieties (Ministry of Population and Environment 2004). Additionally, early warning systems for storms and excessive rainfall will be beneficial for farmers who can plan for such events.

Failure to adapt in the agricultural sector can also lead towards food insecurity (Agrawala et al. 2003). Increased efficiency in storage and transportation of food products within the nation as well as enabling livelihood opportunities 
are essential to ensure food security. Agriculture sector also aids in mitigation as the biomass can count as carbon sink and in some case also serve as alternative fuel.

Nepal is already familiar with the challenges of natural disasters like floods and landslides. Historical trend in precipitation pattern in Nepal shows increase in the annual variation (Practical Action 2009). This suggests the changes of excess water flow will increase leading to flooding and sediment transfer. Moench (2010) has also suggested the threats of flooding and sedimentation will increase with projected climate change. The author further stresses that any coping measure should be based on understanding how local communities respond to the dynamic nature of rivers (Moench 2010). In extreme cases, relocation of infrastructures, farmlands and even villages may be necessary. This however will be very costly and impractical for Nepal. Other forms of structural flood control and bank protection will also be effective downstream but will ensure high public cost.

Increased risk of GLOF and increased run-off variability from glacier retreat also pose threat to hydro-electricity plants. For existing power plants, relocation is a costly adaptation measure. However, investment in smaller power-plants is an adaptation strategy.

Changes in vegetation pattern are expected in Nepal from climate change impacts. In some cases, environmental changes might cause whole forests to disappear (Ministry of Population and Environment 2004). Managing ecosystem services and protecting biodiversity by land-use management will prove beneficial for mitigation as well. Invasive plants have been observed to move towards higher altitudes and compete with native species (Malla 2008). While all of the threats pose danger to natural and social environment, it is not practical to deal with all threats immediately. A framework to evaluate the possible adaptation measures is discussed next.

\section{Evaluative Framework}

There are myriad of adaptation actions against climate change impacts. The actions generally require a long term investment in terms of finance and manpower and should be selected on the basis of what is apt for the location, which utilizes the advantage of autonomous adaptation by the environmental and social systems, and which yields more benefits than cost involved. A list of criteria for evaluating adaptation option is given in Table 2.
Based on these criteria and a list of possible adaptation options, a scoring matrix (Table 3 ) can be charted to compute how each option contributes to fulfilling the criteria. The scoring matrix helps to evaluate adaptation options for a particular case or a location against selected criteria. In the matrix, each selected category receives a rating on a scale that facilitates comparison. The scales can be simple numeric scale like low, high, medium for cost, or it could be more complex for categories like efficiency. Moreover, the weight that each facto gets is left to the decision-makers and stake-holders (USAID 2007).

According to Stringer et al. (2009), the evaluation of adaptation measures can be carried out by rating each adaptation measure based on different criteria. Stakeholders can select a list of specific criteria to be used and develop a weighting scheme for the criteria by rating the level of importance of each of the criteria. Certain criteria may also hold more weight than others in specific locations. A systematic method of rating scores for each criterion should be agreed beforehand. The rating itself can be based on stakeholder and expert judgment or more detailed research and rigorous analysis. A matrix showing the measures and scores of the measures in each criterion can then be used to compare the range of measures and help policy makers in short-listing of measures for immediate action (Stringer et al. 2009). The scoring matrix hence can aid in selecting the measures which are most feasible to implement based on a set of pre-qualified criteria. As an illustration, Table 3 shows a possible matrix to evaluate adaptation options applied to the case of Nepal. The scoring matrix is not to single out the adaptation measure that is best, but to select a bundle of measures which creates benefits but at the same time are easiest to implement. The scoring along each criterion is shown using a nominal scale of 'low', 'medium' and 'high' depending upon the range of expected values for that particular criterion. The actual cost, effectiveness, technical feasibility and cultural feasibility of the measures will require a deeper analysis and may require a separate study. The scores presented in the table are based on the preliminary discussion on the measures discussed in this report and should not be taken as a definite conclusion.

The cost of a measure is handled by the government (public costs) or the individual households (private) or a combination of both. For water conservation and management, the cost at public level will be in terms of controlling leakages and avoiding inefficiencies; education campaigns encouraging 
Table 2. Evaluation criteria for adaptation option [from Simpson et al. (2008) and USAID (2007)].

\begin{tabular}{|c|c|}
\hline Criteria & Description \\
\hline Cost & Costs to implement and maintain; cost sharing possibilities; private and public costs \\
\hline Effectiveness & $\begin{array}{l}\text { Capacity to solve problems or realize opportunities derived from climate change impacts (e.g., } \\
\text { economic benefits, costs avoided, lives saved) }\end{array}$ \\
\hline Ease of Implementation & Potential legal, political, institutional, barriers \\
\hline Acceptability to Local Stakeholders & $\begin{array}{l}\text { All stakeholder identi? ed adaptations are attractive to some stakeholders, but may not be } \\
\text { equally attractive to all stakeholders for political, economic, social or cultural reasons }\end{array}$ \\
\hline $\begin{array}{l}\text { Acceptability to Financing } \\
\text { Agencies/Ministries/Donors }\end{array}$ & International donor support; willingness of ? nancing agencies/ministries involved \\
\hline Endorsement by Experts & Is the option consistent with international best practice \\
\hline Timeframe & $\begin{array}{l}\text { Are short-term or long-term strategies more desirable; How does the timeframe needed to } \\
\text { implement the option compare with that available (e.g., are there specific project or funding } \\
\text { time horizons); }\end{array}$ \\
\hline Institutional Capacity & $\begin{array}{l}\text { How much additional capacity building and knowledge transfer is required to implement the } \\
\text { adaptation }\end{array}$ \\
\hline Size of Bene? ciaries Group & $\begin{array}{l}\text { Does the adaptation provide small benefits to a large number of stakeholders and people or } \\
\text { large benefits to a small number }\end{array}$ \\
\hline $\begin{array}{l}\text { Potential Environmental or Social } \\
\text { Impacts }\end{array}$ & $\begin{array}{l}\text { Are there possible adverse impacts on the environment or people (e.g., contribution towards } \\
\text { greenhouse gas emissions) }\end{array}$ \\
\hline Capacity to Sustain Over Time & Once implemented, can the adaptation be successfully sustained? \\
\hline
\end{tabular}

water conservation; the cost of regulatory agency. The public cost will be the household's reduction in water use. The effectiveness of that measure will be in terms of how it can protect the region from climate change event like extended period of drought and high temperature. Technical feasibility will take into account facts and figures on possible amount of savings in water based on resource trend and behavior of individuals. The data for this will require a more rigorous analysis and surveys which are currently missing. Relocation of farmlands and villages will be costly for government assuming the compensation for land and loss of non-farm land (for instance native forest) to replace farmlands. It will also be costly for farmers at individual or household level to relocate their residence and leave their home. The effectiveness of this measure will be the degree of protection in case of an extreme weather event. The cultural feasibility of this will be the acceptance of relocation by the people which I think will be difficult as due to attachment with the land and surroundings. Reallocation of small, privately owned power plants will also prove expensive but the risk avoidance is certain and will definitely support disaster preparedness as well. Developing an early warning system for disasters and making the citizens prepared for disasters will require cost on the public side but will be highly effective adaptation for climate change as well as disaster planning.

\section{Policy Directions}

From the scoring matrix, the following five measures are probable choices for implementation based on their effectiveness and feasibility over costs incurred. The measures include: (1) water conservation and management; (2) investment in smaller hydro-power plants; (3) research/ planting of climate resistant crops; (4) diversification of agriculture; (5) development of early warning system for disasters; and (6) flood control measures downstream.

The scoring matrix with inputs, based on the review of available literature and organizational capability some of the issues dealing with climate change adaptation is discussed here. As the scoring here is based on preliminary overview only, the list of measures are only to outline the scoring mechanism and will require further analysis for a more conclusive list. The full range of adaptive responses to climate change in Nepal is out of scope for this paper.

The enormity of the problems of climate change demands policies for adaptation which span across different fields and 
Table 3. Scoring matrix for adaptation measures.

\begin{tabular}{|c|c|c|c|c|c|c|c|c|}
\hline Adaptation Measures* & Cost (Public) & Cost (Private) & Effectiveness & $\begin{array}{l}\text { Technical } \\
\text { Feasibility }\end{array}$ & $\begin{array}{l}\text { Social and } \\
\text { cultural } \\
\text { Feasibility }\end{array}$ & Speed & $\begin{array}{l}\text { Support for } \\
\text { Mitigation }\end{array}$ & $\begin{array}{c}\text { Support for } \\
\text { Disaster } \\
\text { Preparedness }\end{array}$ \\
\hline $\begin{array}{r}\text { Water conservation and } \\
\text { management }\end{array}$ & low & low & low & medium & medium & high & low & low \\
\hline Water harvesting & low & medium & low & medium & medium & high & low & low \\
\hline Relocation of farmlands & high & high & high & high & medium & medium & low & high \\
\hline Relocation of villages & high & high & medium & low & low & low & low & high \\
\hline $\begin{array}{r}\text { Relocation of hydropowr } \\
\text { plants (assuming privately } \\
\text { owned) }\end{array}$ & medium & high & medium & high & medium & medium & low & high \\
\hline $\begin{array}{r}\text { Investment in smaller } \\
\text { power plants }\end{array}$ & medium & medium & medium & high & high & high & high & high \\
\hline $\begin{array}{r}\text { Planting climate resistant } \\
\text { crops }\end{array}$ & medium & medium & high & medium & medium & medium & low & medium \\
\hline $\begin{array}{r}\text { Diversification of } \\
\text { agriculture }\end{array}$ & medium & medium & high & medium & medium & medium & low & high \\
\hline $\begin{array}{l}\text { Develop early warning } \\
\text { system of weather disasters }\end{array}$ & high & low & high & medium & high & high & low & high \\
\hline $\begin{array}{r}\text { Listing of adaptive and } \\
\text { endangered plant/animals }\end{array}$ & medium & low & medium & medium & high & low & low & low \\
\hline $\begin{array}{r}\text { Forest and land use } \\
\text { management }\end{array}$ & medium & low & medium & medium & medium & low & high & low \\
\hline Expansion of irrigation & high & high & high & medium & high & medium & low & medium \\
\hline $\begin{array}{r}\text { Development of insurance } \\
\text { sector }\end{array}$ & high & high & medium & high & medium & low & low & high \\
\hline $\begin{array}{r}\text { Hood control measures } \\
\text { downstream }\end{array}$ & high & medium & high & medium & medium & low & low & high \\
\hline
\end{tabular}

different levels. This however leads to the dangers of a policy clash between higher and local level policies. The interaction of different levels of policy towards climate change concerns has been described by Urwin and Jordan (2008) as 'policy interplay' which sometimes facilitates but sometimes also hinders adaptation concerns. Adaptation measures hence should be studied for their wider and long-term impact rather than just the immediate impacts. Goals of climate change adaptation are sometimes similar to other development and disaster planning goals. An understanding of the overlaps in goals is essential to avoid policy clash.

The task of avoiding the unintended consequences on other sectors or other policies is referred to as climateproofing. "Climate proofing means identifying risks to a development project, or any other specified natural or human asset, as a consequence of both current and future climate variability and extremes, and ensuring that those risks are reduced to acceptable levels through long-lasting and environmentally sound, economically viable, and socially acceptable” (Asian Development Bank 2005).

Uncertainty should be built in the system of adaptation planning and evaluation, and whenever possible, adaptation measures which ensures a positive benefit even if climate change impacts as anticipated do not occur should be applied.
These specific cases where the implementation cost of adaptation is lower than non-climate benefits are referred to as 'no-regret' options. Enhancing the ability of social systems and the environment to cope with changes will be beneficial now and in future and these 'no-regrets' measures are easily adopted as policies (USAID 2009).

\section{Conclusion}

Considering the vulnerability of Nepal to adverse effects of climate change in multiple sectors planned adaptation measures is the appropriate action. As development fund is already competing with pressing issues in Nepal, proper prioritization measure for adaptation measures is necessary. Investment in disaster preparedness and strengthening the response capacity is a no-regrets action that will prove beneficial even without climate change. An adaptation strategy consists of a set of measures that can be implemented with little cost, have high effectiveness, and are feasible technically and socially. Additional consideration can include the speed at which the measure can be executed, the contribution of the measure towards mitigation and aid in disaster preparedness. Adaptation measures which are optimal for a location can be selected based on criteria that are identified by the stakeholders 
prior to listing the possible measures. After the list of adaptation is identified, a scoring matrix can be charted to score the measures based on the identified criteria to select the optimal set of measures. In the case of Nepal, adaptation is the areas of water conservation and management, investment in smaller hydro-power plants, research/planting of climate resistant crops, diversification of agriculture, development of early warning system for disasters and flood control measures downstream appear as measures that can be implemented to ensure high degree of benefits with low cost and high acceptability. Understanding the interplay of adaptation actions with other development measures and climate-proofing of government actions can avoid clash of policies,

\section{References}

Agrawala S., Raksakulthai V., Aalst M.V., Larsen P., Smith J. and Reynolds J. 2003. Development and Climate Change in Nepal: Focus on Water Resources and Hydropower. Organisation for Economic Co-operation and Development (OECD), Paris, France.

Asian Development Bank. 2005. Climate Proofing: A Riskbased Approach to Adaptation. Asian Development Bank, Philippines.

Barnett J. 2001. Adapting to climate change in Pacific Island countries: the problem of uncertainty. World Development 29: 977-993.

Cornell A. 2010. Small actor, big opinion: least developed countries participation in climate change networks. Procedia - Social and Behavioral Sciences 4: 59-70.

Downing T.E., Ringius L., Hulme M. and Waughray D. 1997. Adapting to climate change in Africa. Mitigation and Adaptation Strategies for Global Change 2: 19-44.

IPCC. 2007. Fourth Assessment Report. UNFCCC, New York, USA.

Malla G. 2008. Climate change and its impact on Nepalese agriculture. The Journal of Agriculture and Environment 9: 62-71.

Ministrey of Enviornment. 2010. Government of Nepal NAPA Report. Government of Nepal, Ministry of Environment, Kathmandu, Nepal.

Ministry of Population and Environment. 2004. Initial National Communication to the Conference of the Parties of the United Nations Framework Convention on Climate Change. Government of Nepal, Ministry of Population and Environment, Kathmandu, Nepal.

Moench M. 2010. Responding to climate and other change processes in complex contexts: challenges facing development of adaptive policy frameworks in the Ganga Basin. Technological Forecasting and Social Change 77: 975-986.
Parry M., Arnell N., Hulme M., Nicholls R. and Livermore M. 1998. Adapting to the inevitable. Nature 395: 741.

Practical Action. 2009. Temporal and Spatial Variability of Climate Change in Nepal (1976-2005). Practical Action, Kathmandu, Nepal.

Regmi B. and Paudyal A. 2009. Climate Change and Agrobiodiversity in Nepal: Opportunities to Include Agrobiodiversity Maintenance to Support Nepal's National Adaptation Programme of Action (NAPA). Local Initiatives for Biodiversity, Research and Development (LI-BIRD), Pokhara, Nepal.

Sharma R.H. and Shakya N.M. 2006. Hydrological changes and its impact on water resources of Bagmati watershed, Nepal. Journal of Hydrology 327: 315-322.

Shrestha A.B., Wake C.P., Mayewski P.A. and Dibb J.E. 1999. Maximum temperature trends in the Himalaya and its vicinity: an analysis based on temperature records from Nepal for the period 1971-94. Journal of Climate 12: 2775-2786.

Simpson M.C., Gössling S., Scott D., Hall C.M. and Gladin E. 2008. Climate Change Adaptation and Mitigation in the Tourism Sector: Frameworks, Tools and Practices. United Nations Environment Program (UNEP), University of Oxford, UNWTO, WMO, Paris, France.

Smit B. and Pilifosova O. 2001. Adaptation to climate change in the context of sustainable development and equity. In: Climate Change 2001: Impacts, Adaptation, and Vulnerability (J.J. McCarthy, O.F. Canziani, N.A. Leary, D.J. Dokken, K.S. White, eds.), pp. 877-912. Press Syndicate of the University of Cambridge, Cambridge, UK.

Smit B., Burton I., Klein R.J. and Street R. 1999. The science of adaptation: a framework for assessment. Mitigation and Adaptation Strategies for Global Change 4; 199-213.

Stringer L.C., Dyer J.C., Reed M.S., Dougill A.J., Twyman C. and Mkwambisi D. 2009. Adaptations to climate change, drought and desertiûcation: local insights to enhance policy in southern Africa. Environmental Science and Policy 12: 748-765.

Tiwari K.R., Awasthi K.D., Balla M.K. and Sitaula B.K. 2010. Local People's Perception on Climate Change, its Impact and Adaptation Practices in Himalaya to Terai Regions of Nepal. [online] URL: http://www.forestrynepal.org/ publications/article/4837 (assessed 10 20, 2010, from Forestry Nepal).

Urwin K. and Jordan A. 2008. Does public policy support or undermine climate change adaptation? Exploring policy interplay across different scales of governance. Global Environmental Change 18: 180-191.

USAID. 2007. Adapting to Climate Variability and Change: A Guidance Manual for Development Planning. United States Agency for International Development (USAID), Washngton, DC, USA.

USAID. 2009. Adapting to Coastal Climate Change: A Guidebook for Development Planners (Working Draft). [online] URL: http://www.crc.uri.edu/download/ CoastalAdaptationGuide.pdf (assessed 04 22, 2010, from University of Rhode Island Coastal Resource Center Graduate School of Oceanography). 